\title{
EtNoBotánICA de SYNANDROSPADIX VERMITOXICUs (ARACEAE) EN EL Gran Chaco y en REgiones aledañas
}

\author{
PASTOR ARENAS ${ }^{1}$
}

\begin{abstract}
Summary: Ethnobotany of Synandrospadix vermitoxicus (Araceae) in the Gran Chaco and neighbouring regions. Synandrospadix vermitoxicus is a native species of the Gran Chaco (Bolivia, Paraguay and Argentina) and neighbouring regions. An ethnobotanical investigation was conducted with the aim of summarising vernacular knowledge on the plant: common names, uses, its role in social and cultural life, as well as stressing the interest and value attached by human groups of the region. This paper is a summary of original data obtained in situ, in addition to those recorded in bibliographic sources. Oral information and herbarium material was collected during fieldwork carried out with eight ethnic groups, as well as with natives-criollos (local non-indigenous people) from Argentina and Paraguay. In order to contextualise the ethnobotanical information, brief references on the taxonomy, floristics, morphology, ecology, and phytonymy associated with this plant are added. Notes are also included on the plant's role in different cultural settings: food, medicine, veterinary practice, magic, toxicology, mythology and witchcraft. Attention is drawn to the value of the plant for the ethnic peoples and settlers in the Gran Chaco and the interest it holds for them. The need to preserve it as natural and cultural heritage is also expressed.
\end{abstract}

Key words: Gran Chaco Indians, Economic Botany, Plants and Culture, Plants and society, Vernacular names.

Resumen: Synandrospadix vermitoxicus es una especie nativa del Gran Chaco (Bolivia, Paraguay y Argentina) y regiones aledañas. Se realizó una investigación etnobotánica con el fin de compendiar el conocimiento vernáculo referido a la planta: nombres comunes, usos, conocimientos varios, así como su papel en la vida social y cultural de distintos pueblos que habitan en las regiones donde crece. Este trabajo constituye una síntesis que reúne datos originales obtenidos in situ así como aquellos registrados por variadas fuentes bibliográficas. La información oral y el material de herbario se recolectó durante trabajos de campo con ocho grupos étnicos así como con criollos de Argentina y Paraguay. Para contextualizar la información etnobotánica se agregan breves referencias sobre taxonomía, florística, morfología, ecología y fitonimia vinculadas con esta planta. Asimismo, se incluyen notas sobre su rol en diversos ámbitos de la cultura: alimentación, medicina, veterinaria, magia, toxicología, mitología y hechicería. Se resalta el valor e interés que tiene la planta entre las etnias y pobladores del Gran Chaco. Asimismo, se señala la necesidad de su conservación como patrimonio natural y cultural.

Palabras clave: Indígenas del Gran Chaco, Botánica Económica, Plantas y cultura, Plantas y sociedad, Nombres vernáculos.

\section{INTRODUCCIÓN}

Synandrospadix vermitoxicus (Griseb.) Engler es un elemento florístico característico de la flora del Gran Chaco, con distribución predominante

\footnotetext{
1 Centro de Estudios Farmacológicos y Botánicos, CEFyBO-CONICET, Facultad de Medicina, Universidad de Buenos Aires, Paraguay 2155, Piso 16 (1121), Buenos Aires, Argentina. E-mail: pastorarenas@yahoo. com.ar
}

en su porción centro-occidental, extendiéndose en áreas periféricas del piedemonte andino. Su interés y valor actual se da de manera preferencial entre la gente del Chaco semiárido, particularmente entre los pueblos cazadores-recolectores que sobreviven en la región. Sin embargo, en todos los sitios donde crece, los lugareños, ya sean nativos o campesinos, la conocen, la nombran y ocasionalmente la utilizan. En este trabajo se estudia esta planta desde la óptica de la etnobotánica, haciendo notar de esta forma su relevancia entre los humanos que se relacionan 
con ella. La etnobotánica, además de documentar el conocimiento vernáculo, pretende resaltar el valor de la planta en su contexto natural y cultural e intenta contribuir a su salvaguarda y conservación.

Las aráceas son plantas frecuentemente mencionadas por su utilidad o por desempeñar determinados roles en la vida social y cultural en muy diversas regiones del mundo (von Reis \& Lipp, 1982: 19-22; Rivera Núñez \& Obón de Castro, 1991: 1050). Muchas de ellas son ampliamente conocidas por su valor ornamental, rubro en donde son distintivas y generan un activo comercio. Quizá la más representativa sea la "cala" [Zantedeschia aethiopica (L.) Spreng.], pero se destacan igualmente numerosos representantes de los géneros Anthurium, Caladium, Dieffenbachia y Monstera, que son valorados tanto por su follaje como por sus vistosas flores. Un apreciable número de especies pertenecientes al Nuevo Mundo fueron también señaladas por sus propiedades medicinales y alimenticias, aunque sus cualidades abarcan un variado espectro de categorías de uso y de significados culturales (Reitz, 1957: 68-69; Schultes, 1962; Plowman, 1969; Croat, 1994; Crisci, 1971; Crisci \& Gancedo, 1971; Schultes \& Raffauf, 1990: 81-95). Asimismo, las aráceas figuran habitualmente en los listados de plantas tóxicas, sobre todo aquellas especies que poseen látex. Los principios activos causantes de estos efectos se atribuyen a saponinas, glucósidos cianogenéticos, alcaloides, enzimas proteolíticas, entre otros, pero se resalta de manera especial los efectos de los cristales de oxalato de calcio, presentes en rafidios distribuidos en distintos órganos de estas plantas (Plowman, 1969: 97-98; Schultes \& Raffauf, 1990: 81-95; Rivera Núñez \& Obón de Castro, 1991: 1050). S. vermitoxicus aparece ocasionalmente en contribuciones científicas de carácter general donde se le señalan algunas propiedades en forma sucinta, casi siempre sólo como tóxica y/o para curar parásitos del ganado; estas referencias serán citadas y comentadas a lo largo de esta contribución.

Las investigaciones etnobotánicas en el Gran Chaco se inician en la década de 1960 con un trabajo de Martínez Crovetto (1964) que trató sobre los tobas del este del Chaco argentino. Sin embargo, fue a partir de 1970 que se intensificaron las investigaciones por parte de varios autores; éstas se realizaron con diversas etnias asentadas en los territorios de Bolivia, Paraguay y Argentina. Reseñas sobre dichos aportes se encuentran en tres contribuciones que dan cuenta de lo realizado así como las carencias y los tópicos desconocidos (Arenas, 1987; 2009; Arenas \& Martínez, 2012: 26-30).

Esta contrición forma parte de investigaciones etnobotánicas que el autor lleva a cabo entre grupos humanos del Gran Chaco a partir de la década de 1970. Su finalidad prioritaria consiste en la recopilación del conocimiento tradicional sobre el medio ambiente, particularmente aquel referido a la vegetación. El objetivo propuesto en primera instancia es salvaguardar el patrimonio cultural y lingüístico, así como contribuir con datos genuinos que sirvan para resaltar la importancia de los componentes de la naturaleza de la región, gravemente amenazada por presiones externas y ajenas a los intereses de sus habitantes ancestrales. Al mismo tiempo, más allá del valor académico de las informaciones obtenidas en dichas investigaciones, se fija como objetivo que los datos recopilados y ordenados sirvan como material de consulta a nivel técnico y educativo en las comunidades nativas y rurales, y que -en suma- se constituyan para estas sociedades en un testimonio de su historia y les sirva para revalorar y proteger su entorno. En este trabajo, se plantean los objetivos mencionados para el caso específico de $S$. vermitoxicus.

En este trabajo se sintetiza un conjunto de informaciones etnobotánicas referidas a $S$. vermitoxicus que fueron obtenidas durante trabajos de campo en el Gran Chaco. La información registrada se refiere a un total de ocho grupos indígenas que habitan en dicha región y también se incluyen datos que provienen de campesinos o criollos que viven en el área de distribución de la planta. Este material documental constituye el aporte principal de este trabajo. Sin embargo, en esta investigación se incluyen también datos sobre la planta que provienen de la revisión de fuentes bibliográficas que tratan sobre la mencionada región o zonas aledañas. La síntesis, que reúne ambas vertientes -la investigación in situ y la revisión bibliográfica-, nos permite poner de relieve esta valiosa especie nativa que cuenta con numerosos atributos, reconocidos y valorados por los lugareños, pero que en el ámbito de la etnobotánica cuenta con referencias someras. 


\section{MATERIAL Y MÉTOdo}

La investigación se basó en trabajos de campo y en la búsqueda de datos en fuentes bibliográficas. La información etnobotánica fue obtenida durante entrevistas in situ realizadas entre distintos grupos humanos habitantes del Gran Chaco: indígenas (ayoreo, choroti, guaraní occidentales, lengua-maskoy, maká, nivaclé, toba y wichí) y -limitadamente- entre campesinos criollos (Fig. 1). Estos trabajos se iniciaron en 1974 y se extendieron hasta 2014. Se aplicó como fundamento metodológico los lineamientos generales de las etnociencias, particularmente en su enfoque cualitativo (Arenas \& Martínez, 2012). Las referencias orales fueron logradas durante conversaciones informales y en otros casos durante entrevistas de carácter general y exhaustivo mediante la aplicación de una guía etnobotánica general (Arenas, 1995). Se recurrió a informantes calificados así como también se registraron datos provenientes de participantes casuales; en ciertos casos se anotaron observaciones que surgieron como parte de la convivencia en el lugar. Los informantes fueron seleccionados según distintos criterios (sexo, edad, representación o rol social, etc.), tomándose en cuenta el consenso de la comunidad en cuanto a los conocimientos y responsabilidad de la persona elegida. Se prefirió el testimonio de aquellos que tuvieron una experiencia de vida protagónica relacionada con la temática indagada, es decir, cuando los datos reunidos estaban aún vigentes en su sociedad. Las investigaciones de campo no se encararon como temática específica sobre esta planta: la información y el material reunido surge del corpus etnobotánico total relevado. Los datos orales recogidos se documentaron en cintas magnetofónicas y/o en cuadernos de campo que conserva el autor.

Se encaró una amplia revisión bibliográfica, haciendo hincapié en aquellas referencias secundarias que conforman temáticas extraetnobotánicas, como son las fuentes históricas, geográficas, florísticas, fitoquímicas, farmacéuticas, folklóricas, etnográficas y lingüísticas. Todo este material documental registrado se considera en este trabajo al mismo nivel que los datos de campo, y se incorporan tanto en los resultados como en la discusión y conclusiones.
El material vegetal se colectó en compañía de los informantes encuestados durante salidas en el campo. Éste fue preparado según las habituales pautas de herborización, y fueron incorporados en las colecciones de herbarios reconocidos, tanto por su valor documental como para el cotejo y la verificación posterior. Los pliegos de referencia se conservan en forma mayoritaria en el Herbario del Museo Argentino de Ciencias Naturales "Bernardino Rivadavia" de Buenos Aires (BA), así como en otras instituciones según hacemos constar al citar el material estudiado, que en este trabajo se limita al que documenta el trabajo etnobotánico. Se consultaron también otras colecciones depositadas en herbarios representativos de la región (BA, BAF, BAB, CORD, CTES, LIL, LP, PYFQ) y en algunos de Europa (G, MA y P) con el fin de recabar información consignada en las etiquetas: datos sobre el hábito, la distribución geográfica, las características del lugar de colecta, la fenología, pero por sobre todo aquellas anotaciones que involucran la nomenclatura vernácula, así como las observaciones y las apreciaciones que apunta el colector sobre la planta. Se examinó un total de 113 pliegos adicionales, a los que se suman 23 ejemplares conservados en herbarios, que no fueron vistos en esta investigación, pero son citados por especialistas (Crisci, 1971: 258-260; Croat \& Mount, 1988: 37; Gomes Gonçalves, 2002: 112; Novara, 2012: 7). No obstante, en esta contribución no se consigna esta exsiccata adicional en aras de la brevedad del artículo.

Material estudiado. PARAGUAY. Dpto. Boquerón, Colonia Fernheim, Colonia 22, $27-$ II-1981, Arenas 1816 (BA, CTES); Filadelfia, III-1981, Arenas 1850 (BA, CTES, SI); Mariscal Estigarribia, Misión Santa Teresita, II-2014, Arenas 3790 (CTES, FCQ). Dpto. Presidente Hayes, Colonia Menno, Loma Plata, 4-XII-1974, Arenas 1050 (BA, SI); Fn. Gral. Bruguez, 7-I1980, Arenas s.n. (BACP 1650, BA, CTES, SI). ARGENTINA. Prov. Salta: Dpto. San Martín, 50 $\mathrm{km}$ al E de Aguaray, sobre la ruta que va a Santa María, 7-I-1984, Arenas 2576 (BA, H). Dpto. Rivadavia, Coronel Juan Solá (Morillo), Barrio Mataco, 8-I-1983, Maranta \& Arenas 161 (BA, CTES, SI); Coronel Juan Solá, 20-II-2005, Suárez 92 (BA). Prov. Formosa: Dpto. Bermejo, cruce de camino entre Vaca Perdida y Quebracho, 30- 


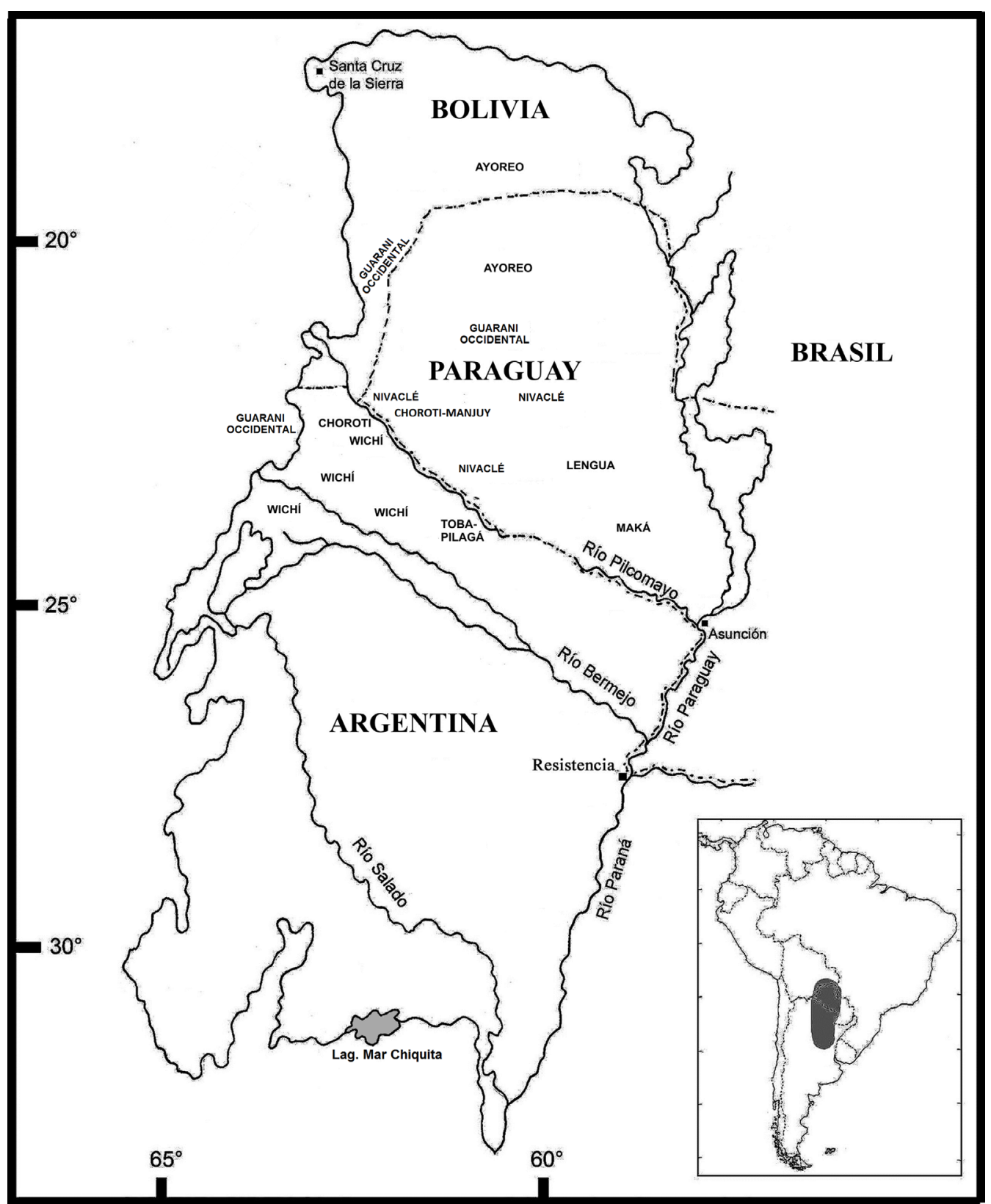

Fig. 1. Localización de las etnias estudiadas en el Gran Chaco.

X-1985, Maranta 1226 (BA); Pocitos, 16-X-1985, Maranta 869 (BA); Ruta entre Vaca Perdida y Pozo de Maza, 2-XII-1985, Arenas 3111 (BA, CTES); Pozo de Maza, 18-II-1989, Arenas 3410 (BA). Dpto. Matacos, Campo Grande, II-1998, Scarpa 62 (BA).

\section{Resultados y Discusión}

\section{La planta}

Es una hierba latescente, terrestre, que alcanza cerca de $1 \mathrm{~m}$ de altura (Fig. A-B). El órgano subterráneo es un tubérculo globoso o achatado, 


\section{P. Arenas - Etnobotánica de Synandrospadix vermitoxicus}

de hasta $15 \mathrm{~cm}$ de diámetro, que puede adquirir 2-3 kilogramos de peso (Fig. 2 F). Las raíces son carnosas y blanquecinas, están dispuestas en la parte superior del tubérculo, semejando una cabellera, de cuyo centro emergen las hojas y las inflorescencias (Fig. 2 E). Durante su floración produce varias inflorescencias que surgen en forma simultánea. Éstas se asientan sobre un pedúnculo de hasta $29 \mathrm{~cm}$ de longitud. El espádice está incluso dentro de una espata navicular, llamativa, que en su parte interna tiene tonos purpúreos y externamente es verdosa; en ambas caras lleva máculas longitudinales, semejando estrías, de color castaño rojizas en el interior y verdosas o rojizas en el exterior. Las hojas son simples, pecioladas y con vaina amplia en la base; las láminas son enteras, cordiformes, ovado-triangulares. Los frutos son bayas globosas $\mathrm{u}$ ovoideas, rojizas al madurar, de cerca de $1 \mathrm{~cm}$ de diámetro; la espata es persistente y envuelve los frutos, que están reunidos en una infrutescencia cuya forma recuerda una mazorca (Fig. 2 D). Varias monografías sobre aráceas, o artículos que tratan sobre esta especie, traen descripciones minuciosas, con abundante información y detalles sobre la morfología y su forma de vida; a estas obras remitimos para conocerla en detalle (Engler, 1883: 59-62; Hooker, 1892; Domínguez, 1903: 267-268; Souto \& Milano, 1966: 387; Cocucci, 1966; Crisci, 1971: 255-260; Croat \& Mount, 1988: 34-37; Crisci \& Katinas, 1997: 13-14; Novara, 2012: 6-7; Gomes Gonçalves, 2002: 112).

\section{Sobre la nomenclatura y la taxonomía}

La planta fue originariamente descripta por Grisebach (1874: 199-200) como Asterotigma vermitoxicum sobre la base de un ejemplar colectado por el botánico alemán Paul Günter Lorentz en 1871 en la provincia argentina de Córdoba. El mencionado autor, sin dar mayor precisión de localidad indica: "Cordoba, ad sepes et inter frutices" (Córdoba, en setos y entre arbustos). Aquel material tipo fue descrito con "Hojas (...) profundamente bipinatífidas" [Folium (...) profunde bipinnatifidum). Grisebach (1874) basó su estudio original en un ejemplar incompleto, cuya única hoja tenía apariencia bipinatífida, lo cual motivó que le asignara al género Asterostigma (Engler, 1883: 6061; Hooker, 1892: tab. 7242; Baillon, 1895: 472; Crisci, 1971: 260). En una posterior contribución, gracias a nuevas colecciones recibidas desde
Argentina, Grisebach da más detalles sobre las características de la planta, y rectifica la descripción de la morfología foliar y da a conocer el nombre vernáculo "sacha col", quizá el más difundido en el noroeste argentino (Grisebach, 1879: 282). Hunziker (1960: 297-298) realizó un detallado estudio de los ejemplares tipo que sirvieron a Grisebach para describir una cuantiosa nómina de nuevas especies de la región, de los cuales se conserva un gran número en el Museo Botánico de Córdoba. El mencionado autor concluye que el isótipo de esta especie, A. vermitoxicum, fue colectado por Lorentz en la localidad cordobesa de Horco-Sumi, en fecha VI-1871, y le corresponde el $\mathrm{N}^{\mathrm{o}} 27$ de su colección. El dato aclaratorio no es menor, ya que Grisebach no mencionaba el número ni las fechas del material que estudiaba; tampoco daba mayores precisiones sobre las localidades de colecta. El holótipo conservado en Córdoba, que tuvimos la oportunidad de consultar, consta de una hoja astada entera, y tres inflorescencias, como ya señalara Hunziker (1960: 298). Asimismo, entre las colecciones del Museo de Córdoba se conserva una fotografía del holótipo, perteneciente al Herbarium de Göttingen, donde se observa una hoja y una inflorescencia que parecen haber sido atacadas por insectos ${ }^{2}$. Con posterioridad a la publicación original de Grisebach de 1874, y la posterior de 1879 , hubo una serie de cambios nomenclaturales que surgieron gracias al análisis de nuevas y más completas colecciones, así como una correcta interpretación de la morfología floral. Éstos fueron emprendidos por Adolf Engler, quien realizó un detallado y minucioso estudio sobre la planta y concluyó en 1883 con la creación del género monotípico y su respectiva especie, Synandrospadix vermitoxicus, el cual persiste hasta la actualidad (Engler, 1878: 203; Engler, 1879: 517; Engler, 1883: 59-62; Engler, 1889: 144; Engler 1920: 49-50). Ajeno a estos eventos,

\footnotetext{
2 Resulta sorprendente que las hojas del ejemplar fueran roídos de una manera tan metódica, al punto que se produzca una forma "bipinatifida", que pueda confundir a A. Grisebach. Los insectos causan estragos en el material de herbario, incluso llegan a deteriorarlos por completo. No tuvimos oportunidad de estudiar este material, pero consideramos que sería plausible una revisión de esta hoja del holótipo. Si tuviera hojas con las características descriptas, no hay que descartar que pueda ser el resultado de una mezcla en el envío o en el proceso de acondicionamiento del material en el herbario.
} 
Bol. Soc. Argent. Bot. 51 (2) 2016

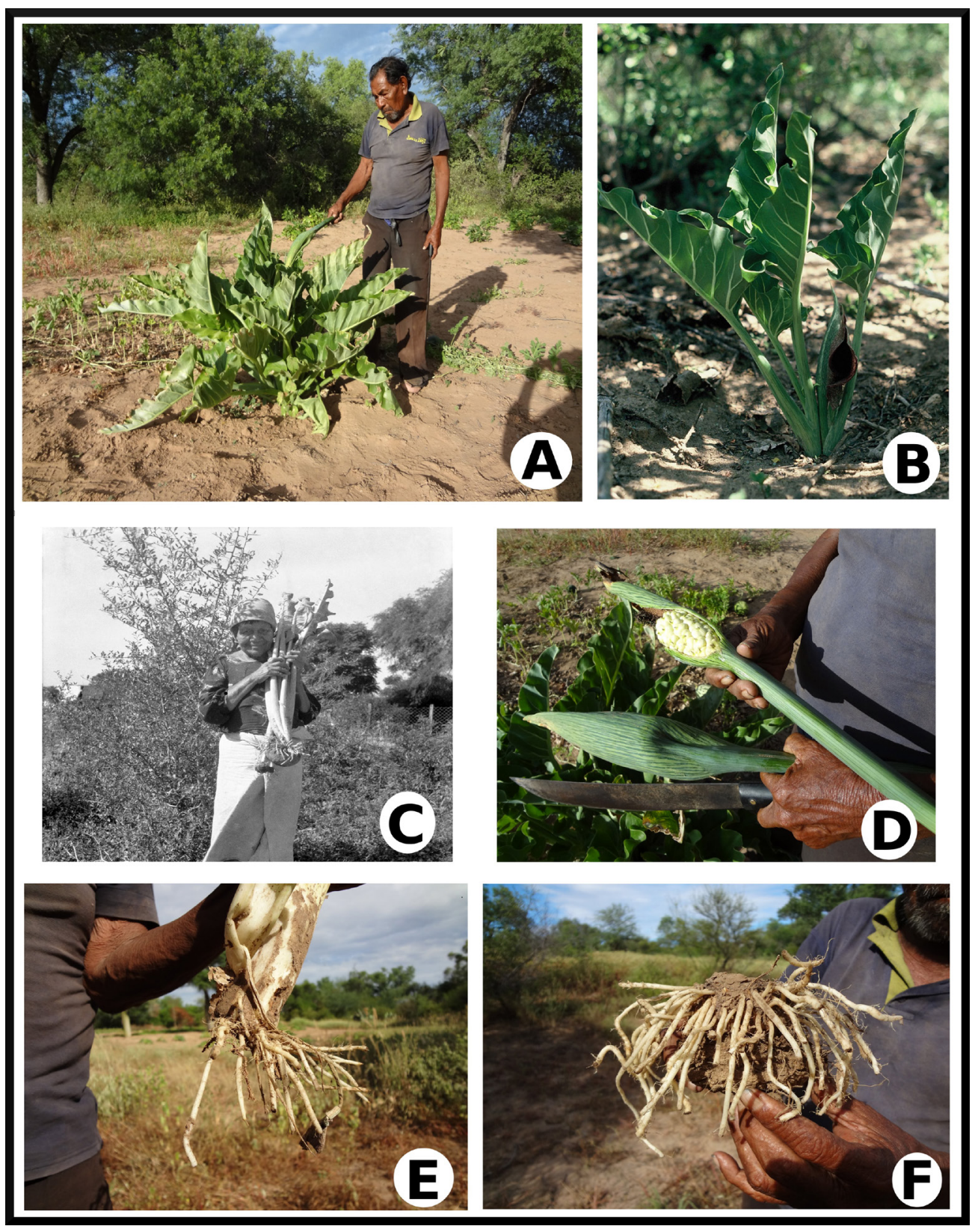

Fig. 2. Synandrospadix vermitoxicus: A: Indígena nivaclé con planta espontánea en su huerto. B: Planta en flor en sotobosque. C: Mujer wichí colecta tubérculos. D: Infrutescencia. E: Base de la planta, inserción de partes vegetativas. F: Tubérculo y raíces. Foto C: Enrique Palavecino, permiso por cortesía del Museo Etnográfico "Juan B. Ambrosetti”, Buenos Aires. Otras fotos: P. Arenas.

el botánico italiano Carlo Spegazzini también describió en 1896 un nuevo género monotípico para designar a esta planta (Spegazzini, 1896: 389392), sorprendiéndose que hasta esa fecha no fuera descripta siendo esta planta tan llamativa como frecuente. Lo denominó Lilloa, en honor al ilustre botánico tucumano Miguel Lillo, y le asignó a la única especie -Lilloa puki- el epíteto específico 


\section{P. Arenas - Etnobotánica de Synandrospadix vermitoxicus}

“puki”, su nombre vernáculo aplicado en Tucumán. Este binomio se consideró como sinónimo a partir de unos años después (Hauman \& Vandenverken, 1917: 232; Hicken, 1922: 232; Crisci, 1971: 256).

Las aráceas están escasamente representadas en la flora del Gran Chaco. Según los registros florísticos recientes suman 6 especies (Crisci, 1971; Croat \& Mount, 1988; Crisci \& Katinas, 1997; Novara, 2012). La mayor parte de ellas se hallan en las porciones húmedas del oriente o Bajo Chaco (Anthurium paraguayense Engl., Phylodendron tweedieanum Schott, Spathicarpa hastifolia Hook. y Taccarum weddellianum Brogn.). En los territorios xeróritos y orófitos está presente $S$. vermitoxicus, en tanto que Pistia stratiotes L. se halla en toda la región, en cuerpos de agua más o menos permanentes.

En lo que concierne a los trabajos etnobotánicos referidos al Gran Chaco, hay que señalar que se registraron muy pocas especies en los respectivos listados conocidos hasta el presente. La información asequible señala: 2 especies para 4 etnias: toba (Martínez Crovetto, 1964), lengua-maskoy (Arenas, 1981), maká (Arenas, 1983) y toba-pilagá (Arenas, 1993). Para los vilela (Martínez Croveto, 1965) y pilagá (Filipov, 1993) se refiere 1 sola especie. El mayor número de aráceas con datos etnobotánicos corresponde a los ayoreo, con 4 especies, entre las cuales, sin embargo, no figura $S$. vermitoxicus (Schmeda-Hirschmann, 1994: 135-136; 1998: 22). De estas 4 especies citadas, 2 se aprovechan por sus órganos subterráneos comestibles (Spathicarpa hastifolia y Taccarum weddellianum). En este trabajo agregamos y confirmamos el uso comestible de $S$. vermitoxicus, lo cual nos revela que los ayoreo son los indígenas chaqueños que conocen el mayor número de aráceas comestibles en la región (en total 3 especies), y asimismo constituye el grupo étnico con mayor registro de conocimiento y aplicación de las aráceas (5 especies).

\section{Hábitat}

Habita en suelos sueltos, ocasionalmente arcillosos, en arenales, en el interior de montes abiertos o matorrales xerófitos de la región. Los hábitats orófitos son roquedales presentes en llanuras cercanas a serranías, en laderas bajas con arbustos o bosques, que se dan tanto en la Prepuna $\mathrm{y}$ el Monte como en los sectores orientales de transición de las Yungas (Cárdenas, 1953: 9; Crisci,
1971: 259-260; Braun Wilke et al., 1995: 200). En el Chaco Centro-Occidental, con rasgos semiáridos, pudimos observarla en suelos arenosos, siempre en sitios elevados, no sujetos a inundaciones persistentes; no prospera en suelos anegadizos, sobre todo en aquellos marcadamente arcillosos que se endurecen luego de las lluvias. Un ámbito que le resulta particularmente propicio son los taludes o lomadas; también los suelos removidos de terrenos de cultivos (Fig. 2 A). Aunque también se la encuentra en el interior de bosques, su comportamiento es preferentemente heliófilo (Fig. 2 B). En la vasta región donde vive es, sin embargo, una planta relativamente escasa: si bien prospera en determinados sectores o sitios, en extensas zonas es inhallable. Este dato fue también observado por otros autores (Ulmke \& August, 2004: 23; Barboza et al., 2006: 109). Se trata pues de una planta poco accesible, por lo que quienes la utilizan la buscan en lugares previamente conocidos.

\section{Biogeografia}

Las primeras colectas de la planta datan de fines del siglo XIX y provienen de las serranías del noroeste argentino, puntualmente del Chaco Serrano, por lo cual las primeras referencias la mencionan como "planta andina" propia de Argentina (Engler, 1883: 62; Hooker, 1892: tab. 7242; Engler, 1920: 50). Las posteriores colecciones verificaron su presencia en Bolivia, Paraguay y Argentina, mencionándose en varias monografías botánicas las provincias y departamentos donde habita (Hassler, 1909: 40; Fiebrig \& Rojas, 1933: 25; Foster, 1958: 38; Crisci, 1971: 258-260; Croat \& Mount, 1988: 37; Crisci \& Katinas, 1997: 14; Gomes Gonçalves, 2002: 112). Más allá de los límites políticos implicados, hay que reiterar que la planta es una especie característica del Gran Chaco sudamericano y que se expande limitadamente en áreas adyacentes que corresponden a otras regiones fitogeográficas. Como la especie prevalece en el Gran Chaco se impone aclarar que éste comprende dos amplias zonas delimitadas por sus respectivos patrones de lluvia: al este la porción húmeda o Bajo Chaco y al oeste el Chaco seco o semiárido, cuyo límite se da en el piedemonte andino, que por sus peculiaridades suele tratarse como una subregión a la que nombran Chaco Serrano (Morello \& Hortt, 1985; Morello et al., 2009). Mediante la revisión de ejemplares en herbarios y citas en referencias 
bibliográficas florísticas, se debe subrayar que $S$. vermitoxicus habita en forma preferencial en el occidente del Gran Chaco semiárido y serrano, y penetra en áreas vecinas, tanto en sus bordes septentrionales, occidentales y meridionales. Estos lugares comprenden las Provincias fitogeográficas de Yungas, del Monte y de la Prepuna (Cabrera, 1971; Crisci, 1971; Cabrera \& Willink, 1973). El mapa de distribución de Gomes Gonçalves (2002: 112) ilustra adecuadamente su área de distribución. Sobre la base de los sitios de colecta estudiados durante esta investigación se pudo establecer que su límite al $\mathrm{N}$ se encuentra en el Sudeste de Bolivia, en la lat. $18^{\circ} \mathrm{S} 64^{\circ} \mathrm{O}$ (Dpto. Santa Cruz, Prov. Caballero). A partir de esta latitud se expande hacia el sur, a lo largo del noroeste argentino hasta el centro de dicho país (Provincias de Córdoba y Catamarca), alcanzando aproximadamente la lat. $31^{\circ} \mathrm{S}$ (Prov. Córdoba, Dpto. Cruz del Eje). Al $\mathrm{O}$ está presente en el Chaco serrano y penetra en áreas montañosas hasta los $2000 \mathrm{~m}$ en la Prepuna, Yungas y Monte. Sobre su presencia en la porción oriental y húmeda del Gran Chaco existe poca documentación, no contándose con registros más allá de la long. $58^{\circ} \mathrm{O}$ en el Chaco paraguayo. En este sector oriental la planta no llegaría sino apenas al S del río Bermejo (Prov. Chaco, Dpto. Gral. Güemes, $21^{\circ} \mathrm{S}, 61^{\circ} \mathrm{O}$ ). De esta revisión surge que esta planta no estaría presente en las porciones orientales cercanas a la zona de influencia de los ríos Paraguay y Paraná.

La literatura florística amplió equivocadamente su presencia por fuera de estos límites, lo cual impone hacer dos rectificaciones: la primera concierne a la provincia argentina de Corrientes, y la segunda a Perú. Para el primer caso, Crisci (1971: 258) y Crisci \& Katinas (1997: 14) mencionan esta especie en la provincia argentina de Corrientes, basándose en un ejemplar dudoso. Este material es estéril, sin localidad ni colector, y nada indica que corresponda a esta entidad [ARGENTINA. Prov. Corrientes, Dpto. Bella Vista, sin localidad, sin colector, 31-V-1923 (BAB)]. Según aclaramos en el párrafo precedente, los límites de $S$. vermitoxicus no traspasan la franja ecotonal de los ríos Paraguay y Paraná, por lo que se deberá excluir esta provincia argentina de su área de distribución. También se debe advertir sobre la cita que indica su presencia en Perú. El dato se basa en un ejemplar de herbario colectado por el botánico alemán
August Weberbauer [PERÚ. Dpto. Cusco, Prov. Quispicanchi, Weberbauer 7953, 23-II-1929 (F)], erróneamente identificado, el cual se conserva en el Field Museum of Natural History de Chicago (Brako \& Zarucchi, 1993: 81). La fotografía del material nos fue proporcionada por la institución y mostró claramente que se trata de otra especie, lo cual fue corroborado por E. Gomes Gonçalves (comunicación personal), reconocido especialista en Spathicarpeae.

\section{Nombres vernáculos}

Se registró una amplia lista de nombres vernáculos en lenguas nativas así como en el español regional. Un aporte especial de este trabajo es el registro de fitónimos que le asignan las etnias del Chaco, el cual se resume en la Tabla 1. Estos vocablos son utilizados y conocidos sólo en el interior de cada una de estas sociedades. Algunos nombres incluidos en el cuadro fueron extraídos de la bibliografía; en esos casos se respetan las notaciones consignadas por los autores ${ }^{3}$. Junto con los nombres propios de las etnias estudiadas, existen otros que le asignan los criollos, campesinos e hispanohablantes, es decir, son aquellos fitónimos propios del idioma de contacto, que es el español regional. Estos nombres vernáculos fueron registrados en numerosas fuentes escritas, figuran en las etiquetas de herbario y también los hemos escuchado in situ. Seguidamente haremos una revisión de estos fitónimos regionales. En el sudeste de Bolivia son varios: "papa-papa" (Herzog, 1916: 93-94; Kempff Mercado, 1976: 13; Peña, 1976: 80; Gomes Gonçalves, 2002: 112), "papa katari” (Gomes Gonçalves, 2002: 112), "guaya" (Tárraga \& Hart, 1995). El nombre de origen guaraní "mangara" está difundido en el área ocupada por los guaraní occidentales y es la voz que se difundió entre la población campesina (de Nino, 1912: 87; Giannecchini, 1916: 100; Herzog, 1916: 93-94; Cárdenas, 1953: 9; Gomes Gonçalves, 2002: 112). El nombre "mangara" se aplica, en efecto, entre los guaraní occidentales que habitan en el Chaco boliviano y paraguayo, así como en poblaciones guaraní asentadas en las provincias argentinas de Salta y Jujuy. Si bien este fitónimo tupí-guaraní se aplica en el Chaco occidental a $S$. vermitoxicus, es posible que se asigne también

\footnotetext{
3 Tanto en nuestras notaciones como en las de la bibliografía se dan variantes; esto es así porque se trata de lenguas de tradición oral y no cuentan con un alfabeto o modalidad de escritura estandarizada y consensuada.
} 


\section{P. Arenas - Etnobotánica de Synandrospadix vermitoxicus}

Tabla 1. Nombres vernáculos de S. vermitoxicus según etnias chaquenses

\begin{tabular}{|c|c|c|}
\hline Grupo étnico & Familia lingüística & Nombre vernáculo \\
\hline \multirow{2}{*}{ Ayoreo } & \multirow{2}{*}{ Zamuco } & doéha \\
\hline & & dóineha \\
\hline \multirow{3}{*}{ Choroti } & \multirow{3}{*}{ Mataco } & $\begin{array}{l}\text { I) láap-láap-itié (Scarpa, 2007: 102; Arenas \& } \\
\text { Scarpa, 2007: 82) }\end{array}$ \\
\hline & & $\begin{array}{l}\text { II) sijyé, sihié (Scarpa, 2007: 102; Arenas \& Scarpa, } \\
\text { 2007: 82) }\end{array}$ \\
\hline & & III) (choroti-manjuy) shihie\#, shihie\#eta \\
\hline $\begin{array}{l}\text { Guaraní Occidental } \\
\text { (chiriguano, guarayo, } \\
\text { tapiete, guaraní ñandéva) }\end{array}$ & Tupí-guaraní & mangara \\
\hline Lengua & Maskoy & yaatip pomlhek \\
\hline Maká & Mataco & ceqjitec \\
\hline \multirow{6}{*}{ Nivaclé } & \multirow{6}{*}{ Mataco } & sishaaj \\
\hline & & sashaaj \\
\hline & & kanitkai \\
\hline & & kanitke \\
\hline & & cônitc'ay \\
\hline & & kanit'kai \\
\hline \multirow{3}{*}{$\begin{array}{l}\text { Toba-pilagá, toba } \\
\text { ñachilamole'ek }\end{array}$} & \multirow{3}{*}{ Guaycurú } & qaiGea'Ga la'ta\#a \\
\hline & & naqaigea'Ga la'ta\#a \\
\hline & & nehikia'Ga la'ta\#a \\
\hline \multirow{3}{*}{ Wichí } & \multirow{3}{*}{ Mataco } & sĩhĩox \\
\hline & & sih'nyox \\
\hline & & sinhyoj \\
\hline
\end{tabular}

-como un genérico- a otras aráceas, aún a aquellas que son cultivadas (Gatti, 1985: 180).

En territorio argentino, los nombres "sacha col" y "mata vaca" son los más difundidos; ambos son citados por varios autores (Grisebach, 1879: 282; Hooker, 1892: tab. 7242; Spegazzini, 1896: 390; Domínguez, 1903: 267; Durañona \& Domínguez, 1904: 171; Bodenbender, 1941: 60; Villafuerte, 1961: 265; Souto \& Milano, 1966: 385; Sayago, 1969: 273; Ragonese, 1967: 66; Schulz, 1976: 189; Toursarkissian, 1980: 10; Braun Wilke et al., 1995: 200; Barboza et al., 2006: 109; Osán de Pérez Sáenz \& Pérez Sáenz, 2006: 739; Scarpa, 2012: 177; Novara, 2012: 6). Otros nombres menos mencionados, y quizá menos difundidos, son: "sapera" (Barboza et al., 2006: 109; Novara, 2012: 6), "sacha papa" (Braun Wilke et al., 1995: 200; Novara, 2012: 6), "choclo de zorro" (Braun
Wilke et al., 1995: 200) y "pela mano" (Crisci, 1971: 258, Crisci \& Katinas, 1997: 14; Scarpa, 2012: 177; Novara, 2012: 6). El nombre "puqui”" o "puki" parece circunscripto a Tucumán y provincias vecinas (Spegazzini, 1896: 390; Schulz, 1976: 189; Novara, 2012: 6), lo cual pudo comprobarse en etiquetas de herbario correspondientes a dichas provincias. Hay que señalar que se desconoce a qué lengua nativa regional correspondería el nombre "puki"; las investigaciones realizadas al respecto en varias lenguas habladas en la región, tanto en el pasado como en la actualidad (quichua, aymara, lule, tonocoté, entre otras), han sido hasta el momento infructuosas. No tenemos datos sobre nombres asignados por los criollos paraguayos.

Los nombres vernáculos listados suelen revelar las cualidades y características de la planta. Éstos dan indicios sobre sus aplicaciones, sobre sus 
efectos, sus peculiaridades morfológicas, sus semejanzas con otras plantas, entre otros elementos que los hablantes toman en cuenta para nominar. No se profundizó en cada nombre, pero se presenta un par de ejemplos para ilustrar el mecanismo de asignación de nombres. En el caso del nombre vernáculo "choclo de zorro" (choclo= fruto tierno del "maíz", Zea mays L., el segmento "choclo" se motiva por la infrutescencia cubierta por la espata, tal como ocurre con el "maíz" (Fig. 2 D), mientras el segmento "del zorro" quizá se deba a que se observó que lo consume algún tipo de "zorro" (quizá el "zorro Pampa", Ducicyon gymnocercus, Canidae) que habita en la región. El nombre "sacha col" se aplica en el noroeste argentino, región donde se habló y se habla aún en algunas zonas la lengua quichua, y se compone de los segmentos "sacha" = voz quicha: semejante, falso, silvestre; "col" = se asigna a la planta hortícola "repollo" o "col". El nombre refiere al color de las hojas, que son de un verde ceniciento, un tanto suculentas, y se asemejan a las del "repollo" o "col" (Brassica oleraceae L., Brassicaceae)

\section{S. vermitoxicus y una arácea vinculada con ella}

Durante entrevistas con etnias asentadas en territorio paraguayo, que abarcó a los lenguamaskoy, maká, nivaclé y manjuy (una parcialidad montaraz choroti, que habita en suelo paraguayo), numerosos informantes mencionaron una planta muy similar a la especie que tratamos, que por las descripciones de su aspecto y sus cualidades permite asociarla sin dudas con una arácea. Según estos datos la especie es comestible y palatable, y su consumo no reviste peligros. La consideran la "verdadera" entidad apta para la alimentación, asegurándonos que $S$. vermitoxicus es un sucedáneo o sólo una planta parecida. Hay que apuntar tres observaciones al respecto: 1) la planta fue inhallable en todos estos años, y afirman que ya no es posible encontrarla, no se la ve por ningún lado, 2) según parte de las informaciones es una planta cultivada, de excelente sabor, pero que ya no la plantan, 3) otros datos la describen como planta nativa. Las referencias sobre esta planta fueron escuchadas por nosotros a partir de la década de 1970 entre los lengua-maskoy y se repiten aún hoy entre los ancianos de todas las etnias mencionadas. Un breve repaso sobre los datos reunidos in situ es como sigue. Los lengua-maskoy distinguen yaatip pomlhek (S.vermitoxicus) de pomlhek, que es la planta parecida pero de sabor grato. Los maká repiten la misma situación, nombrando ceqjitec a $S$. vermitoxicus, ceqji a la planta ignota. Los nivaclé mencionan los nombres sishaaj o sashaaj, claramente adjudicada a S. vermitoxicus (Stahl, 1982: 32; V. Regehr y M. Moreno, com. pers.; nuestros datos propios). Reunimos también el nombre kanitkai, kanitke, cônitc'ay que algunos atribuyen a $S$. vermitoxicus, pero otros datos afirman que este es el nombre que le pertenece a la planta muy parecida con tubérculos también comestibles (Com. personal, V. Regehr \& M. Moreno). Sin embargo, por las opiniones encontradas entre ambos nombres nivaclé, pareciera que ambas voces coexisten y pueden darse alternativamente a $S$. vermitoxicus. Una referencia destacable es el extenso y detallado párrafo que le dedica Chase Sardi (2005: 237) al tubérculo comestible nombrado conic'ai, planta que aclara nunca pudo ver, pero indica sus características, atributos y forma de uso, los cuales coinciden completamente con $S$. vermitoxicus. Agrega un dato interesante, "esta planta suele ser transplantada por las mujeres desde la selva hasta los cercos (huertos) de cultivo". Los choroti-manjuy repiten el mismo esquema antes mencionado: conocen como shihie\#, a la planta cultivada inocua, en tanto nombran shihie\#eta a la planta montaraz, que requiere de un largo proceso para su consumo. Las confusiones o datos imprecisos reproducidos en este ítem son producto de recuerdos difusos y comentarios que se transmiten de una generación a otra. Éstos aportan en primer lugar datos llamativamente coincidentes en grupos humanos distintos con respecto a una planta hoy inhallable. La reconstrucción temporal nos hizo suponer que se trataría de una arácea comestible y cultivada que fuera conocida y difundida hasta aproximadamente los años de la década de 1950. Esto se sustenta también en las noticias del agrónomo R. H. G. Lowes, un religioso de la Iglesia Anglicana que enseñó técnicas agrícolas modernas a jóvenes lengua-maskoy en los años 1947-49 (Lowes, 1954: 85). Este misionero apunta el nombre katte yi, aplicado por los lenguamaskoy y su equivalente "coco-yam" en inglés y da la identificación Colocasia antiquorum, aunque quizá se trataría de C. esculenta (L.) Schott. Esta planta sería bien conocida por Lowes, ya que se trata de un cultígeno difundido en regiones del 


\section{P. Arenas - Etnobotánica de Synandrospadix vermitoxicus}

trópico y subtrópico. Nunca pudimos ver a esta especie en ningún huerto de estos grupos indígenas, pero responde a las características y cualidades que evocaron nuestros ancianos informantes. El hecho de que la conocieran los maká, lengua-maskoy, nivaclé, y la mencionaran aún los montaraces manjuy, se explicaría por la extensa labor realizada por los misioneros ingleses a fines del siglo XIX y primeras décadas del XX en el Chaco paraguayo, labor que implicó a numerosas etnias de la región (Stahl, 2007: 177-182; Ratzlaff, 2008: 81-85; Powell, 2010).

\section{Percepción del aroma y el sabor}

La literatura, así como las etiquetas de herbario, suelen informar sobre el olor que despide la inflorescencia desde su apertura hasta su senescencia. Presentamos un breve resumen donde se señalan las percepciones según diversas fuentes consultadas. Estos datos nos revelan un interesante campo, prácticamente inexplorado en etnobotánica, el de la antropología del olor y del sabor, lo cual nos muestra cómo datos concretos varían en la percepción de las personas. Spegazzini (1896: 392) informa que "las inflorescencias y las espatas fructíferas despiden un olor pesado, repugnante, viroso, y al podrirse lo cambian en olor de conicina ${ }^{4}$ muy fuerte y característico". Domínguez (1903: 268) consigna, asimismo, que las inflorescencias exhalan un olor "fuerte y viroso". Souto \& Milano (1966: 387) resaltan el olor fétido que emiten las hojas y el tubérculo al ser cortados. Peña (1976: 81) explica que contiene jugo cáustico y exhala olor cadavérico, y agrega que el "olor fétido del espádice atrae las moscas". Nuestras anotaciones propias, y las que figuran en etiquetas de herbario revisadas, consignan testimonios tales como: "inflorescencia fétida", "espádice fétido", "inflorescencia con olor pútrido", "inflorescencia con olor a carne podrida", hasta apreciaciones más amables como manifiestamente contrarias, como es el caso que le adjudica un colector: "aroma intenso y agradable". Otro aspecto se refiere al sabor, del cual - sin embargo- contamos con escasas referencias. Al respecto, Maranta (1987: 202) describe el léxico de los gustos y sabores en lengua wichí y reproduce cómo la perciben a esta planta cuando

\footnotetext{
4 Se refiere al olor fétido de la conicina, coniína o cicutina, un alcaloide presente en la "cicuta" (Conium maculatum L., Apiaceae).
}

la comen: tuj ok'aj = me come la lengua. Otra expresión, usada por los wichí de la parcialidad lhukutáx, es la voz tuuk\#an, que equivale a pungente, picante, y es el mismo término que se aplica a la sensación que produce el "ají del monte" (Capsicum chacoense Hunz., Solanaceae). Entre los choroti pertenecientes al grupo dialectal denominado iyojwája, la nombran láap-láap-itié (= arde-arde adentro), según la traducción de Scarpa (2007: 93, 102).

Los usos, sus aplicaciones y su papel en la cultura de los pueblos

Alimenticio

Se cuenta con datos fidedignos sobre su empleo como alimento entre varias etnias del Gran Chaco: ayoreo, choroti, nivaclé, lenguamaskoy, wichí y guaraní occidentales. Quienes la emplean sospechan, o bien aseguran, que es una planta venenosa y resaltan que es imposible consumirla sin un adecuado tratamiento previo. $\mathrm{Su}$ sabor desagradable e irritante requiere de un procedimiento de cocción que lo vuelva palatable. De los numerosos relatos recabados se desprende, que a pesar de las distintas formas de cocción sugeridas, el producto no resulta del todo agradable. Los lengua-maskoy hierven el tubérculo durante varias horas y hacen unos cuantos cambios de agua; se acostumbra asarlo previamente al hervor (Arenas, 1981: 134; Polini et al., 2013: 154). Los wichí lo asan en primer lugar y luego se lo somete a sucesivos hervores, durante varias horas, con 5-6 cambios de agua. Para asar se procede de varias maneras. Se asan enteros o se cortan en trozos, que luego se colocan sobre las brasas, se chamuscan un poco, luego se desecan al sol, y por fin se hierven. De este modo se le extrae su mal sabor y su atribuida toxicidad, aunque mencionan que persiste el sabor picante (Métraux, 1946: 247; Maranta, 1987: 180; Arenas, 2003: 259-260). Los wichí ya no lo consumen desde hace décadas, pero eran frecuentes usuarios (Fig. 2 C $^{5}$ ). Suárez (2014: 193-194) recopiló otros detalles de los wichí referidos a su preparación: una

\footnotetext{
5 Esta fotografía fue tomada por el etnógrafo argentino Enrique Palavecino en las primeras décadas del siglo $X X$. Muestra a una mujer wichí, que habitaba en una localidad del Chaco Serrano. Forma parte de la rica colección documental que guarda el Museo Etnográfico "Juan Bautista Ambrosetti" de la Facultad de Filosofía y Letras, de la Universidad de Buenos Aires.
} 
de las indicaciones recomienda el empleo de leñas con gran poder calorífico, conociéndose el punto de cocción cuando aparece una espuma resinosa en la superficie del sancocho. Los choroti que habitan a la vera del río Pilcomayo refirieron que también la consumían en el pasado, pero los datos obtenidos estaban ya muy desdibujados cuando se realizó la investigación hace una veintena de años atrás. Recordaron que el tubérculo era previamente asado entre cenizas del rescoldo y luego se lo sometía a hervor. Cuentan que lo acompañaban con grasa de pescado y el agregado de sal y "ají del monte" nativo (Capsicum chacoense) (Arenas \& Scarpa, 2007: 82). Otra parcialidad choroti, denominada manjuy, que habita en los bosques del Chaco paraguayo, refiere que asan el tubérculo entre las cenizas del fogón o en el horno subterráneo ${ }^{6}$ y luego lo someten a varios hervores y cambios de agua. Los nivaclé enumeran procedimientos similares a los registrados con los choroti en cuanto a la preparación y recordaron que se comía aderezado con grasa de varios tipos de pescados o de "ñandú" (Rhea americana, Rheidae). Algunas versiones, pertenecientes a los nivaclé que habitan en el monte, indican que su preparación consiste en asarlo al rescoldo, aclaran que no se lo hierve, y se consume directamente sin ningún otro agregado, pese a que "quema la boca". También se menciona su cocción en el horno subterráneo, aunque esta forma de preparación se abandonó por completo hace varias décadas. Los datos ayoreo informan que su preparación consiste en el asado entre cenizas calientes del fogón, donde se lo dejaba durante un tiempo de cocción que era conocido por la cocinera, y una vez a punto, lo consumían directamente. Hay que recordar que los ayoreo vivían en el monte xerófito, con grandes dificultades para acceder al agua, la que en otras etnias se cambia varias veces. Los guaraní del occidente del Chaco (chiriguanos, chanés, tapietés, y otras denominaciones asignadas) están afincados en el Chaco boliviano, paraguayo y argentino; ellos también consumieron en el pasado el tubérculo de esta planta, a la que nombran

\footnotetext{
6 El horno subterráneo de las etnias del Chaco consiste en un hoyo cavado en el suelo, de cerca de $1 \mathrm{~m}$ de profundidad, que se calienta con abundante leña que se hace arder dentro del hueco. Cuando se consume el fuego se coloca el producto a asar, se tapa la boca del horno con ramas de arbustos y tierra encima. Esto se realizaba a última hora de la tarde y a la mañana siguiente el producto estaba listo.
}

"mangara". Consultas realizadas en el Chaco paraguayo indican que el hábito fue abandonado desde mucho tiempo atrás. Sin embargo, sobre el uso de "mangara" existen referencias bibliográficas muy explícitas que se relacionan claramente con S. vermitoxicus. Si bien estos datos son escuetos y pueden prestarse a dudas, consideramos que se pueden adjudicar con gran certeza a $S$. vermitoxicus, y merece que hagamos una breve revisión de las referencias. Una de las más antiguas data del siglo XVIII, la cual proviene del sacerdote jesuita Pedro Lozano, quien relata un encuentro con un grupo de nativos nómades en el actual Chaco boliviano: "sólo unos infieles que se encontraron en el río Parapití apresaron los nuestros, dos muchachos y una muchacha y también un adulto medio simple de los que llaman andantes. Éstos declararon que eran del río abajo del pueblo de Pini, que habían salido por allí en busca de mangara para mantenerse" (Lozano, 1941: 311). Asimismo, el sacerdote franciscano Giannecchini (1916: 100) proporciona una descripción sobre el "mangara" de los chiriguanos: "raíz amarga y muy picante. Los indios usan dicha raíz tan solo en tiempo de mucha carestía. Sus efectos son irritar la boca y producir fuertes dolores de estómago. Hervida mucho tiempo en varias aguas es comestible. Suelen también, en tiempo de carestía, majarla y hacerla fermentar en el agua, para así formar una especie de guarapo". Otro religioso, también franciscano, el padre de Nino (1912: 87), indica que los chiriguanos se ven muchas veces apremiados por las carencias de alimento y suelen recurrir "a la raíz del aro serpentino o mangara, amarga y venenosa antes de cocerla". Estas mismas voces, "mangara" y "aro serpentino", son utilizadas por Peña (1976: 80), quien establece que corresponde a tres especies. Parte de sus descripciones permite asociar a una entidad que se corresponde con $S$. vermitoxicus; el autor indica: "La raíz, si bien acre, la comen los indígenas, después de asada: cuando fresca es purgante violento y peligroso...". En las primeras décadas del siglo XX, numerosos contingentes pertenecientes a estos guaraníes occidentales se afincaron en las llanuras secas del occidente chaqueño paraguayo, luego de la guerra paraguayo-boliviana (1932-1935). De ellos, cuenta González (1968: 283) que "en tiempos de miseria consumen raíces de mangará o mangará 


\section{P. Arenas - Etnobotánica de Synandrospadix vermitoxicus}

iety, especie de "güembé taia", de hojas claras y lanceoladas y raíz bulbosa, que asan o hierven tres veces, cambiando cada vez el agua de cocción". Los datos reproducidos muestran claramente que se refieren a esta especie. Una información más reciente de Tárraga \& Hart (1995) menciona que las raíces de la "guaya" o "mangara" son consumidas por los tobas afincados en territorio boliviano. Nosotros pudimos corroborar que "magara" es, en efecto, el nombre asignado a $S$. vermitoxicus entre los guaraní occidentales paraguayos afincados en la localidad de Mariscal Estigarribia.

Un aspecto que no se puede eludir al tratar la subsistencia de las etnias del Gran Chaco tiene que ver con que padecen un prolongado tiempo de sequías y carestías. Esta es la razón que motivaba el acopio de productos en los meses pródigos de la primavera y el verano. Estas vituallas se desecaban para utilizar en momentos de escasez. En general no hay datos de que el tubérculo de esta planta se conservara en sus conocidos trojes o reservorios, quizá porque su colecta y uso estaba indicado especialmente para el período de penurias. No obstante, Suárez (2014: 193) informa que los tubérculos secados al sol se conservaban en trojas, y aclara que para el momento de consumirlos se procedía de igual modo que cuando están frescos (es decir, en sucesivas cocciones). No hallamos datos de que la planta se emplee como comestible por fuera de las etnias propias del Chaco.

\section{Medicamento}

Hay escasa información sobre su empleo como remedio para los humanos. No obstante, hace tres décadas reunimos datos que informan que antiguamente los toba del oeste de Formosa, o toba-pilagá, como también se los conoce, lo empleaban para tratar el acné (hena'Ga en su idioma). Ancianos informantes contaron que se extrae el tubérculo, se lo deseca, luego se muele y el polvo resultante se coloca encima de las partes afectadas. También reunimos información sobre su uso entre los nivaclé para combatir la tos; para aplicarlo, se machaca la raíz, se la hierve y el zumo se toma por cucharadas durante cuatro días (Verena Regehr, Marcos Moreno, com. personal). Asimismo, los choroti del Chaco salteño refieren que se colocan rodajas del tubérculo encima de

\footnotetext{
7 Nombre que asignan los guaraníes de la Región Oriental del Paraguay a varias aráceas.
}

heridas gangrenosas para cicatrizarlas (Scarpa, 2009: 102).

\section{Magia de amor}

Entre los toba-pilagá, la planta está considerada como dotada de poder para deshacer una relación de pareja. Produce exactamente lo contrario a enamorar, es decir, provoca el desamor, el rechazo, la ruptura, el completo desinterés por el otro o entre ambos, y desencadena el abandono. Lo pueden aplicar tanto los varones como las mujeres. Se procede de muy diversas maneras según las situaciones personales, de quién sea el que manipula el encanto, del entorno familiar, del grado de tensión existente, entre otros motivos. Siempre es el tubérculo el elemento comprometido, el cual, así como la planta misma, están completamente vedados a las personas que conviven como pareja bien avenida, quienes en tal situación no pueden tan siquiera tocarla. Se mencionó que una persona soltera o sola sí puede manipularla. Otro punto importante a tener en cuenta es que el usuario debe realizar la acción de la manera más oculta y secreta pues de lo contrario el remedio se torna inocuo. Una de las formas de proceder consiste en preparar un polvo con el tubérculo y echarlo en la comida de la persona que se desea expulsar. El otro método consiste en que la persona implicada se espolvorea el cuerpo antes de dormir juntos o frota el lecho, en la porción donde se echa a dormir la posible víctima del hechizo. Es un remedio indicado para que una mujer engañada actúe para vengar su despecho y también lo puede usar un varón que desea separarse sin conflictos, por ejemplo de una mujer de mayor edad, que es exigente y desmedida en sus reclamos, o de mal genio. Cuando el hechizo se realiza en forma de comida, la pareja come el plato preparado y aunque duermen juntos, a los pocos días el hechizado aborrece a quien tiene al lado y termina yéndose con sus sentimientos de afecto completamente perdidos. También, cuando una mujer que es víctima de la infidelidad marital, se baña con la decocción del tubérculo hervido; sin mediar palabras ni riñas ella logra el desamor mediante el simple contacto del otro, lo cual se traduce en una silenciosa retirada del hombre, que ya no desea volver, y si regresa ella no lo acepta. Según la información recopilada hay diversas variantes más, que se aplican según la necesidad del caso. Entre los maká se refiere un dato similar, aunque su empleo se circunscribe al 
uso femenino. Cuentan que lo usaban antiguamente las mujeres que vivían en las partes muy alejadas, Chaco adentro, sin duda en las porciones más áridas del hábitat maká. En este caso se da una situación completamente opuesta a la reseñada para los tobapilagá: se busca el amor y/o el apego del varón amado. Se empleaban las hojas y el tubérculo. Se cortaban trozos de ambos órganos, se desecaban y luego los pisaban. Esta materia desmenuzada se guardaba y la interesada, con disimulo y en secreto, la ponía en contacto con el hombre querido para que no la abandone o para atraerlo.

\section{Veterinaria}

$\mathrm{Su}$ papel en la veterinaria y su efecto sobre las larvas se remite a un evidente conocimiento vernáculo muy antiguo que perdura hasta nuestros días. El epíteto específico vermitoxicus (= tóxico para gusanos), asignado en la descripción original de la planta ya dio cuenta de ello, sin duda tomado a partir de observaciones de los colectores de la planta, que fue reproducido a partir de las primeras notas botánicas y florísticas (Grisebach, 1874: 200; Hieronymus, 1882: 279; Engler, 1889: 144; Spegazzini, 1896: 390; Herzog, 1916: 93-94). Estas primeras noticias provienen del centro y noroeste argentino: Córdoba, Tucumán y Salta. Hieronymus (1882: 279), autor del primer compendio sobre plantas usuales de Argentina y regiones vecinas, dio un relato detallado de su empleo en veterinaria y su cualidad tóxica, pero no agregó ninguna otra aplicación. Referencias más recientes dan noticias que amplía el conocimiento sobre sus cualidades. Así, Braun Wilke et al. (1995: 200) consignan que en Jujuy se la conoce como tóxica para el ganado vacuno, equino y porcino. Asimismo, los criollos del Chaco salteño la emplean para tratar las gusaneras del ganado; en este caso, los tubérculos desecados se raspan y los fragmentos se colocan en la herida (Novara, 2012: 7). Similar aplicación dan los criollos del oeste de Formosa, con una modalidad un tanto distinta: se horada con un cuchillo el tubérculo y el líquido que fluye se vuelca sobre la parte afectada; sirve también como desinfectante de heridas en los animales (Scarpa, 2000: 260; Scarpa, 2012: 177). Villafuerte (1961: 265) apunta que en Catamarca, las gentes del campo usan los tubérculos desecados y pulverizados para evitar que las moscas se asienten en las heridas de los animales. En cuanto a los grupos indígenas chaqueños, conocen este uso a través de los criollos. Así, los lengua-maskoy del Chaco paraguayo, aprendieron en los establecimientos ganaderos donde trabajaron como peones rurales, desde comienzos del siglo XX, que los tubérculos brindan un medicamento para tratar las gusaneras de los caballos; para aplicarlo, lo machacan y el jugo obtenido se coloca en la parte afectada (Arenas, 1981: 134). Los nivaclé también le dan este mismo uso; refieren que se raspa el tubérculo, se exprimen las virutas y el jugo se coloca en las heridas de las gusaneras de los animales domésticos, particularmente en las del perro. Este conocimiento propio de los criollos se transmitió a los wichí, quienes en caso de verse en idéntica necesidad también lo aplican. Suárez (2014: 194) reunió una variada información al respecto, sobre todo para el uso en perros. En este caso se aplica una pasta hecha con las hojas, directamente o diluida en agua, o también la decocción del tubérculo. Las referencias en el marco de la farmacobotánica también datan de los inicios del siglo XX; podemos recordar las notas de Domínguez (1904: 269) y Durañona \& Domínguez (1904: 171), quienes describieron su efecto de destruir las larvas que depositan las moscas sobre las heridas de los animales; esta acción farmacológica etiquetan estos autores como "alexítero", una expresión médica antigua que se refiere a un veneno dispuesto externamente para contrarrestar una dolencia.

\section{Tóxica}

Su toxicidad es la cualidad más resaltada en las referencias directas obtenidas en el campo, tanto entre indígenas como entre criollos, así como en los datos consignados en las fuentes escritas. Las referencias bibliográficas, sin embargo, no dan precisiones o detalles sobre los efectos o los síntomas que producen en el afectado ni los antídotos aplicados (Ragonese, 1967: 66; Schulz, 1976: 189; Gallo, 1979: 45-46; Braun Wilke et al., 1995: 200). Esta falta de precisiones ocurre también en la conversación con la gente, por lo que cabe preguntarse si los efectos de su "toxicidad" fueron realmente observados o experimentados por quienes lo refieren; de hecho, no hemos escuchado ningún dato sobre efectos fatales. Sin embargo, quienes tocaron o intentaron arrancar la planta, resaltan el efecto irritante en las manos $\mathrm{u}$ otras partes del cuerpo. Es posible que la ingesta sea muy ocasional 


\section{P. Arenas - Etnobotánica de Synandrospadix vermitoxicus}

o accidental, como suele ocurrir con las aráceas, ya que debido a los efectos de su inmediata acritud se trata de eliminar su acción sobre las partes afectadas (boca, manos, piel en general), y al menos lavar de inmediato con agua. Como se indicó arriba, las fuentes bibliográficas son poco explícitas sobre su acción tóxica, que reseñamos a continuación. En los albores del siglo XX, cuando la planta era novedosa, se señaló que la misma "contiene un principio acre y cáustico que aún no se ha aislado" (Domínguez, 1904: 269; Durañona \& Domínguez, 1904: 171). La información asequible actual tampoco indica que se haya avanzado en forma considerable sobre este punto. Estas mismas referencias aportan Souto \& Milano (1966: 387), quienes efectuaron una encuesta entre pobladores y arrieros de Tucumán, obteniéndose la corroboración de su toxicidad para el ganado. Barboza et al. (2006: 111) señalan, asimismo, que la literatura la menciona como tóxica y cáustica, y agregan que produce dermatosis. Tárraga \& Hart (1995) consignan que las semillas son tóxicas para los animales. Las referencias sobre principios activos tóxicos indican que esta cualidad estaría relacionada con la presencia de glucósidos cianogenéticos, principalmente en hojas jóvenes, y en menor medida en los tubérculos (Souto \& Milano, 1966). Esta breve revisión nos muestra que el ítem relativo a la toxicidad y la fitoquímica de la planta requieren de investigaciones que amplíen y aclaren este atributo en forma convincente.

Distintos autores que se ocuparon de la etnobotánica chaqueña señalaron el apreciable número de plantas alimenticias consumidas, así como la toxicidad o la impalatabilidad de muchas de ellas si previamente no son tratadas para despojarles de sus propiedades negativas (Métraux, 1946; Martínez Crovetto, 1964, 1965; Arenas, 1981, 1982, 2003; Maranta, 1987; SchmedaHirschmann, 1998). Situación parecida se da en muy diversas regiones del mundo, lo cual fue compendiado por Johns \& Kubo (1988) en una minuciosa monografía donde citan las técnicas de desintoxicación aplicadas a 216 especies. Los mencionados autores incluyen 26 especies de aráceas, entre las que -sin embargo- no figura $S$. vermitoxicus.

\section{La planta en la narrativa nativa}

Los lengua-maskoy relataron un nutrido número de mitos sobre vegetales, animales, utensilios de la vida cotidiana, actividades de las personas, así como datos aclaratorios sobre el sentido y razón de ser de las cosas y los hechos que ocurren en este mundo. Aunque ya a fines de los años 70 muchas narraciones estaban siendo olvidadas, uno de nuestros informantes refirió el mito de origen de esta planta (Arenas, 1981: 134). Por el interés que reviste lo transcribimos nuevamente, con una traducción un tanto diferente a la ya conocida: "Hay una historia que apenas conozco, nosotros la llamamos (a esta planta) yaatip pomlhek. Se trata de un hombre que murió y fue enterrado al pie del árbol waalha (Salta triflora (Griseb.) Adr. Sánchez, Polygonaceae). Es un hombre del que se desconoce su nombre, pero se nos cuenta esta breve historia de la planta que vemos y que se relaciona con él. Fue un hombre, dicen, y se convirtió en esta planta. Este señor, entonces, fue sepultado y surgió de él este vegetal, al que nosotros nombramos yaatip pomlhek. Ciertamente, se la come, pero sale mala esta planta, no la podemos consumir directamente. Entonces buscamos la manera de consumirla, y fue así que la gente antigua descubrió cómo poder comerla. Se cocina más o menos y se hierve nuevamente, así se le acaba ese veneno (o enojo, rasgo de maldad $^{8}$ ) que tiene. Si uno va a comer medio cruda esa planta hace arder la garganta". Narrador: Pablo Saavedra, Misión Nueva Vida (Chaco paraguayo), 28-I-1977, Cinta 10(2). De acuerdo al material recopilado en esta etnia, este personaje de los tiempos míticos fue un hombre sin duda poderoso, con seguridad un chamán, que dio origen a esta planta a partir de su cuerpo. Los mitos etiológicos narrados por los lengua-maskoy que informan sobre el origen de plantas, animales, objetos, entre otros dones, suelen conservar rasgos de la personalidad o del carácter del ancestro humano o del ente que lo otorga. Antes de su deceso o transformación, el protagonista suele informar a su pueblo del evento que ocurrirá y cómo debe procederse con lo que se instaura, sobre todo si el legado es de utilidad. Los chamanes lenguas se distinguen por la dualidad de sus personalidades, la maldad y la bondad, que se expresan con claridad en los relatos míticos. En este caso, los rasgos dañinos, venenosos y desagradables de la planta revelan los atributos negativos del lejano

\footnotetext{
8 El informante utilizó el idioma guaraní para narrar esta historia y utilizó la voz pochy, que significa, además de veneno, ira, maldad.
} 
hombre primigenio protagonista, y a la vez nos opone con su faceta positiva, en este caso porque al mismo tiempo es una planta comestible, un obsequio postrero para el bien de su comunidad. Suárez (2012: 159, 161) informa que entre los wichí del Chaco semiárido salteño $S$. vermitoxicus, llamada sihnyoj o Pelhay-k'os en su lengua, antiguamente habría tenido ciertos efectos mágicos para los cazadores. Esto ocurría si alguno tocaba o rozaba la planta -intencionadamente o no- durante la búsqueda de salvajina. El nombre alternativo Pelhayk'os, que asignan a esta planta los wichí de esa región, se traduce aproximadamente como "cultivo del dueño de las tormentas" [(Cultivo de Pelhay (Pelhay = tormentas; "dueño" espiritual de las tormentas; k'os = planta cultivada, cultivo)]. Este nombre, explica la mencionada autora, se debe a que las plantas brotan en la época de lluvia.

\section{Castigo y venganza al hechicero}

Entre los chané, que forman parte del grupo guaraní occidental que habita en territorio argentino, Bossert \& Villar (2004: 54-55) reunieron información donde se menciona el uso del órgano de almacenamiento del "mangara" para realizar un ritual con el fin de vengar la muerte de un familiar provocada por un hechicero. Este ritual vindicatorio se da entre diversas etnias del Gran Chaco y está ampliamente documentado (Arenas, 2012). El evento se realiza para descubrir y castigar al hechicero o chamán maligno que produce el daño cuyo desenlace es la muerte. Son los familiares y allegados de la víctima quienes ejecutan un cruento ritual en el cadáver o en el moribundo con el fin de hacer justicia y vengar al difunto. Existe una abundante literatura al respecto, por cuya razón omitimos los detalles, aunque no obstante, haremos una síntesis del proceso para contextualizar el dato en donde interviene esta planta. El ritual se realiza en el cuerpo del moribundo o en el cadáver del recién fallecido. Consiste en acciones violentas, como fustigarlo con ramas espinosas o palos, aplicarle tizones ardiendo, cortarle partes del cuerpo o herirle, hacharlo o romperle el cráneo, introducir dentro del cuerpo una piedra al rojo vivo, entre otros tormentos. Estas acciones violentas se reproducen o se "contagian" en el culpable. Éste, luego de celebrado el ritual, siente dolores, sufrimientos y efectos similares a lo actuado en el rito, y habitualmente muere como producto de la venganza. Si bien el dato aportado por Bossert \& Villar (2004) es breve, muestra claramente que la materia prima aplicada sirve para desquitarse en el hechicero, y consiste en moler el tubérculo de "mangara", el cual se introduce en las fosas nasales y en el ano del occiso. Los efectos dolorosos y venenosos de la planta se reproducirán en el culpable, produciéndose de este modo su muerte.

\section{Conclusiones}

En el Gran Chaco (Bolivia, Brasil, Paraguay y Argentina) sobreviven en la actualidad un total de 18 etnias pertenecientes a 6 familias lingüísticas (Braunstein \& Miller, 1999; Zanardini \& Biedermann, 2001). Esta región comprende una superficie de alrededor de un millón de $\mathrm{Km}^{2}$, donde se encuentran áreas rurales, pequeños poblados, ciudades y áreas naturales o escasamente habitadas. En este trabajo se pudo reunir referencias sobre el conocimiento y uso de $S$. vermitoxicus entre 8 grupos étnicos así como entre pobladores rurales del Chaco boliviano y del noroeste y centro de Argentina. Faltan aún datos etnobotánicos sobre una decena de etnias, y un mayor conocimiento sobre la etnobotánica folk regional.

Las referencias sobre el uso de esta especie se refieren mayoritariamente a su toxicidad y a su aplicación en veterinaria, en particular para combatir parásitos. Entre las etnias recolectoras la mayor aplicación registrada fue como alimento. No obstante, en esta contribución se recogieron datos sobre otros variados usos y creencias.

La toxicidad en las aráceas se atribuye a compuestos tales como saponinas, glucósidos cianogenéticos, alcaloides, enzimas proteolíticas, sales de oxalato, entre otros. No obstante, las referencias fitoquímicas sobre $S$. vermitoxicus son contadas, y sólo podemos rescatar la contribución de Souto \& Milano (1966: 389-390), quienes revelan la presencia glucósidos cianogenéticos en las hojas y en escasa cantidad en los tubérculos. La carencia de datos experimentales nos impide conocer la naturaleza y causa de sus efectos y propiedades. Sin embargo, hay que subrayar que las descripciones de los nativos sobre la acción de la planta sobre las mucosas, coinciden más bien con el escozor que producen los cristales de oxalato presentes en los rafidios que a consecuencias drásticas sobre el organismo. 
Las técnicas de desintoxicación referidas por Johns \& Kubo (1988) para aráceas, y plantas de otras familias de distintas partes del mundo, concuerdan con varios de los procedimientos mencionados para S. vermitoxicus en nuestra monografía; también coindicen con los que fueron reseñados por otros autores para la desintoxicación de aráceas (Hoehne, 1939: 84; Plowman, 1969; Yanovsky, 1936; Moerman, 2010).

El conocimiento sobre la distribución geográfica de la especie nos muestra que pese a la apreciable exsiccata que tuvimos oportunidad de estudiar (113 pliegos), además de las mencionadas en la literatura pero no vistas (23 pliegos), las colecciones del Gran Chaco aún adolecen de serias carencias. Esto se hace más visible en el Chaco Húmedo, en la región cercana a los ríos Paraguay y Paraná, y también al sur del río Bermejo. Una prueba de esta afirmación es que para la provincia argentina de Formosa, situada entre el río Pilcomayo y el río Bermejo, las únicas colectas que pudimos estudiar son los cuatro ejemplares que forman parte de los estudios etnobotánicos emprendidos por nuestro grupo de trabajo. Asimismo, los ejemplares provenientes de las provincias argentinas de Santiago del Estero y del Chaco, ambas situadas en ámbito netamente chaqueño, las colecciones son de apenas tres ejemplares en cada una de ellas, lo cual muestra un relevamiento muy escaso en regiones donde presumiblemente la planta tendría mayor presencia.

Como resultado de la revisión exhaustiva de la exsiccata se pudo comprobar que esta planta chaqueña no crece al este del ecotono que conforma el área fluvial de los ríos Paraguay y Paraná; de este modo se concluye que no se encuentra en la provincia de Corrientes (Argentina), como se señaló previamente. En su distribución occidental habita hasta las estribaciones andinas, pero no llega a la región cordillerana de mayor altura. Se comprobó que la cita de su presencia en la región de Cusco (Perú) se basa en un ejemplar perteneciente a una arácea identificada equivocadamente, por lo cual la mención de $S$. vermitoxicus en dicho país debe ser corregida.

Como se señaló en párrafos precedentes, $S$. vermitoxicus tiene una distribución geográfica con preeminencia en el occidente del Chaco, la cual comprende territorio boliviano y argentino, así como zonas colindantes del ámbito andino. Este extenso territorio abarca las provincias argentinas de Córdoba, Catamarca, Santiago del Estero, Tucumán, Salta y Jujuy. En suelo boliviano le corresponden los departamentos Santa Cruz, Chuquisaca y Tarija. Estas regiones fueron pobladas desde los albores de la colonización hispana, creándose en ellas incipientes aldeas y centros urbanos que a lo largo de cuatro siglos se acrecentaron y colonizaron vastas zonas de estos territorios. Esto condujo a la paulatina desaparición de los pueblos originarios y en consecuencia sobrevino el cambio sociocultural, con hegemonía por parte de la población mestiza y foránea. Esta configuración social, cuyo perfil económico es netamente extractivo y productivo, implicó que la flora nativa sufriera transformaciones sustantivas que se tradujeron en la deforestación, la explotación agroganadera y el deterioro ambiental general. En este trabajo se mencionan referencias vinculadas con la etnobotánica de $S$. vermitoxicus que se remontan al siglo XVIII, siendo ésta la región de donde provienen las primeras colectas de la especie y los datos sobre su uso En la actualidad, sin embargo, en dichas regiones, los conocimientos y sus aplicaciones serían irrelevantes o inexistentes, y en general no pasan de la mención del nombre vernáculo. Contrariamente, en las planicies del Chaco semiárido, donde aún viven etnias que conservan la lengua y mantienen -en grado dispar- sus culturas tradicionales, $S$. vermitoxicus está aún presente en sus vidas. El objetivo del trabajo etnobotánico emprendido en la región se centró en la documentación del saber tradicional sobre la flora nativa con la finalidad de promover su conservación, así como la salvaguarda del patrimonio cultural. $S$. vermitoxicus aparece en la bibliografía que se citó a lo largo de este trabajo con apenas unos pocos datos, que no sobrepasan breves líneas. Esta compilación logró reunir un espectro amplio de atributos que enriquece el conocimiento sobre ella. En conclusión, se da por cumplida la finalidad concreta de nuestro emprendimiento: la de resaltar el valor de esta curiosa planta, que posee una gran significación cultural para los pueblos del Gran Chaco, y en tal sentido este aporte constituye un material que dota de información para la historia de estos pueblos.

\section{Agredecimientos}

Recordamos con gratitud a los incontables informantes que nos brindaron sus conocimientos; la sabiduría que transmitieron durante estas investigaciones queda reflejada en este artículo. Las instituciones, colegas y amigos que nos apoyaron 
para abordar este trabajo son también numerosos, y mencionamos nuestro reconocimiento a aquellos directamente implicados: A los directores y curadores de los herbarios consultados, por las facilidades y atenciones brindadas. Muy especialmente a Laura Iarleghi del Museo La Plata (Argentina) y a Lorenzo Ramella, del Conservatoire et Jardin Botaniques de Genève (Suiza). Al Museo Etnográfico "Juan B. Ambrosetti", de la Universidad de Buenos Aires, por permitir la publicación de la foto tomada por Enrique Palavecino, la cual forma parte de su acervo. Nuestro reconocimiento a colegas que tuvieron la amabilidad de situar los lugares de colecta de la exsiccata en las respectivas regiones fitogeográficas: Laura Califano, Cristina Perea, Alfredo Grau y Gustavo J. Martínez. A Sergio Cáceres y Matías Acuña, de la Biblioteca del IBONE, Corrientes, por su cooperación en búsquedas bibliográficas, y por igual motivo, a los bibliotecarios del Real Jardín Botánico de Madrid. Asimismo, a Christine Niezgoda y Daniel Le, del Field Museum of Natural History de Chicago, que nos enviaron fotografías. A Diego M. Ruíz, quien tuvo la amabilidad de proporcionarnos la descripción original de Lilloa puki. A los especialistas en aráceas Thomas Croat y Eduardo Gomes Gonçalves por su orientación para resolver dificultades sobre la distribución de la especie. A Verena Regehr, Marcos Moreno y Verena Friessen, de Neuland, Chaco Paraguayo, por proporcionarnos datos e informaciones originales sobre la planta. A María Eugenia Suárez, Nicolás M. Kamienkowski, Lily August y Lawrence Wheeler por sus aportes y cooperación para dar forma a este trabajo. Al Consejo Nacional de Investigaciones Científicas y Técnicas (CONICET) y la Agencia Nacional de Promoción Científica y Tecnológica, ambas de Argentina, por sus aportes financieros para realizar nuestras investigaciones.

\section{Bibliografía}

ARENAS, P. 1981. Etnobotánica lengua-maskoy. Fundación para la Educación, la Ciencia y la Cultura (FECIC), Buenos Aires.

ARENAS, P. 1982. Recolección y agricultura entre los indígenas maká del Chaco Boreal. Parodiana 1: 171-243.

ARENAS, P. 1983. Nombres y usos de las plantas por los indígenas maká del Chaco Boreal. Parodiana 2: 131-229.
ARENAS, P. 1987. La etnobotánica en el Gran Chaco. Memorias, IV Congreso Latinoamericano de Botánica, Simposio de Etnobotánica, pp. 3552. Instituto Colombiano para el Fomento de la Educación Superior, Bogotá.

ARENAS, P. 1993. Fitonimia toba-pilagá. Hacia una Nueva Carta Étnica del Gran Chaco 5: 75-100.

ARENAS, P. 1995. Encuesta etnobotánica aplicada a indígenas del Gran Chaco. Hacia una Nueva Carta Étnica del Gran Chaco 5: 161-178.

ARENAS, P. 2003. Etnografia y alimentación entre los toba-ñachilamole\#ek y wichi-lhuku'tas del Chaco Central (Argentina). Edición del Autor, Buenos Aires.

ARENAS, P. 2009. Los estudios sobre medicina y farmacopea vernácula en el Gran Chaco. Rojasiana 8: 81-100.

ARENAS, P. 2012. Hechicería, muerte y prácticas funerarias para vengar maleficios entre los toba del occidente de Formosa (Argentina). In: ARENAS, P. (ed.), Etnobotánica en regiones áridas y semiáridas del Cono Sur de Sudamérica, pp. 179-193. Edición del CEFYBO-CONICET, Buenos Aires.

ARENAS, P. \& G. J. MARTÍNEZ. 2012. Estudio etnobotánico en regiones áridas y semiáridas de Argentina y zonas limítrofes. Experiencias y reflexiones metodológicas de un grupo de investigación. In: ARENAS, P. (ed.), Etnobotánica en regiones áridas y semiáridas del Cono Sur de Sudamérica, pp. 11-43. Edición del CEFYBOCONICET, Buenos Aires.

ARENAS, P. \& G. F. SCARPA. 2007. Edible wild plants of the Choroti Indians, Gran Chaco, Argentina. Bot. J. Linn. Soc. 153: 73-85.

BAILLON, H. 1895. Aracées. Histoire des plantes 13: 424-515. Librairie Hachette, Paris.

BARBOZA, G. E., J. J. CANTERO, C. O. NÚÑEZ \& L. ARIZA ESPINAR. 2006. Flora medicinal de la provincia de Córdoba (Argentina). Pteridofitas y antófitas silvestres o naturalizadas. Museo Botánico de Córdoba, Córdoba.

BODENBENDER, G. 1941. Nombres vulgares, en orden alfabético, y nombre cientifico de plantas argentinas, silvestres y cultivadas. Imprenta de la Universidad de Córdoba, Córdoba.

BOSSERT, F. \& D. VILLAR. 2004. Acusaciones de brujería entre los chané. Archivos. Departamento de Antropología Cultural, CIAFIC, Buenos Aires 2(1): 149-162.

BRAKO, L. \& J. L. ZARUCCHI. (eds.) 1993. Catalogue of the Flowering Plants and Gymnosperms of Peru. Monogr. Syst. Bot. Missouri Bot. Gard. 45: I-XL, 1-1286.

BRAUN WILKE, R., B. S. VILLAFAÑE \& L. P. E. PICHETTI. 1995. Plantas de interés ganadero 


\section{P. Arenas - Etnobotánica de Synandrospadix vermitoxicus}

de Jujuy y Salta, Noroeste argentino. Secretaría de Ciencia, Tecnología y Estudios Regionales. Universidad Nacional de Jujuy, San Salvador de Jujuy.

BRAUNSTEIN, J. \& E. S. MILLER. 1999. Ethnohistorical introduction. In: MILLER, E. S. (eds.), Peoples of the Gran Chaco, pp. 1-22. Bergin \& Garbey, Westport.

CABRERA, A. L. 1971. Fitogeografía de la República Argentina. Bol. Soc. Argent. Bot. 14: 1-42.

CABRERA, A. L. \& A. WILLINK. 1973. Biogeografía de América Latina. Monografia No. 13. Serie de Biología. Organización de Estados Americanos, Washington.

CÁRDENAS, M. 1953. Un viaje botánico por el sur de Bolivia. Revista Agric., Cochabamba 9: 3-19.

CHASE-SARDI, M. 2005. Economía nivaclé. Suplemento Antropológico, Universidad Católica de Asunción 40(1): 171-265.

COCCUCI, A. E. 1966. Embriología de Synandrospadix vermitoxicus (Araceae). Kurtziana 3: 157-181.

CRISCI, J. V. 1971. Flora argentina: Araceae. Revista Mus. La Plata Secc. Bot. 21: 255-260.

CRISCI, J. V. \& O. A. GANCEDO. 1971. Sistemática y etnobotánica del guembe (Philodendron bipinnatifidum) una importante arácea Sudamericana. Revista Mus. La Plata Secc. Bot. 11: 285-302.

CRISCI, J. V. \& L. KATINAS. 1997. Araceae. Flora Fanerogámica Argentina, ProFlora-CONICET, Fasc. 42: 1-19.

CROAT, T. B. 1994. The use of New World Araceae as drug plants. Japanese J. of Botany 69: 185-203.

CROAT, T. B. \& D. MOUNT. 1988. Araceae. In: SPICHIGUER, R. (ed.), Flora del Paraguay, pp. 5-47. Edit. Conserv. Jard. Bot. Genève \& Miss. Bot. Gard.

DE NINO, B. 1912. Etnografia chiriguana. Tipografía de I. Agote, La Paz.

DOMÍNGUEZ, J. A. 1903. Datos para la materia médica argentina I. La Semana Médica y Librería de Medicina. Buenos Aires.

DURAÑONA, L. \& J. A. DOMÍNGUEZ. 1904. Apuntes de botánica médica II. A. Guidi Buffarini Editor, Buenos Aires.

ENGLER, A. 1878. Araceae. In: MARTIUS, C. F. P. DE \& A. G. EICHLER (eds.), Flora Brasiliensis 3(2): 25-224.

ENGLER, A. 1879. Araceae. In: DE CANDOLLE, A. \& C. (eds.), Monographiae Phanerogamarum 2: 1-681.

ENGLER, A. 1883. Beiträge zur Kenntniss der Araceae III. Engler's Bot. Jahrb. 4: 59-66.

ENGLER, A. 1889. Araceae. In: ENGLER, A. \& K. PRANTL (eds.), Die natürlichen Pflanzenfamilien 2(3): 102-153. Verlag von W. Engelmann, Leipzig.
ENGLER, A. 1920. Araceae-Aroideae und AraceaePistioideae. In: ENGLER, A (ed.), Das Pflanzenreich Regni Vegetabilis Conspectus 4(23 F): 1-274.

FIEBRIG, C. \& T. ROJAS. 1933. Ensayo fitogeográfico sobre el Chaco Boreal. Rev. Jard. Bot. Mus. Hist. Nat. Paraguay 3: 1-87.

FILIPOV, A. 1993. Fitonimia pilagá. Hacia una Nueva Carta Étnica del Gran Chaco 5: 101-119.

FOSTER, R. C. 1958. A catalogue of the ferns and flowering plants of Bolivia. Contr. Gray Herb. 184: $1-23$.

GALLO, G. G. 1979. Plantas tóxicas para el ganado en el Cono Sur de América. EUDEBA, Buenos Aires.

GATTI, C. 1985. Enciclopedia guaraní-castellano de ciencias naturales y conocimientos paraguayos. Arte Nuevo Editores, Asunción.

GIANNECCHINI, D. 1916. Diccionario chiriguanoespañol y español-chiriguano, compilado por los pp. Santiago Romano y Herman Cattumar. Tarija.

GOMES GONÇALVES, E. 2002. Sistemática e evolução da tribo Spathicarpeae (Araceae). Tese de Doutorado, Universidade de São Paulo, São Paulo.

GONZÁLEZ, G. 1968. Entre los guaraní-chané (o ñanaguas) del noroeste chaqueño. Suplemento Antropológico, Revista del Ateneo Paraguayo 3(12): 259-338.

GRISEBACH, A. 1874. Plantae Lorentzianae. Bearbeitung der ersterc und zwieten Sammlung argentischer Pflanzen des Professor Lorenz zu Cordoba. Göttingen.

GRISEBACH, A. 1879. Symbolae ad Floram argentinam. Göttingen.

HASSLER, E. 1909. Contribuciones a la flora del Chaco argentino-paraguayo. Primera Parte. Florula Pilcomayensis. Trab. Mus. Farmacol. 21: 1-154.

HAUMAN, L. \& G. VANDERVEKEN. 1917. Catalogue des Phanérogames de l'Argentine. I. Gymnospermes et Monocotylédones. Anales Mus. Nac. Hist. Nat. Buenos Aires 29: 1-351

HERZOG, T. 1916. Die von Dr. Th. Herzog auf seiner zweiten Reise durch Bolivien in den Jahren. Meded. Rijks-Herb.29: 1-94.

HICKEN, C. 1922. Plantae Vattuonei. Darwiniana 1: 95-153.

HIERONYMUS, J. 1882. Plantae diaphoricae. Florae Argentinae. Imprenta Guillermo Kraft, Buenos Aires.

HOEHNE, F. C. 1939. Plantas e substâncias vegetais tóxicas e medicinais. Graphicars, São Paulo- Rio de Janeiro.

HOOKER, J. D. 1892. Synandrospadix vermitoxicus. Native of Tucuman. Bot. Mag. 48: Tab. 7242.

HUNZIKER, A. T. 1960. Catálogo de los tipos Grisebachianos conservados en Córdoba. Estudio crítico del material de tipos de nomenclatura de las 
especies y variedades descriptas por Grisebach en "Plantae Lorentzianae" y "Symbolae ad Floram Argentinam", existentes en el Museo Botánico de Córdoba. Bol. Acad. Nac. Ci. Republ. Argent. 41: 283-421.

JOHNS, T. \& I. KUBO 1988. A survey of traditional methods employed for the detoxification of plant foods. J. Ethnobiol. 8: 81-129.

KEMPFF MERCADO, N. 1976. Flora amazónica boliviana. Academia Nacional de Ciencias de Bolivia, La Paz.

LOWES, R. H. G. 1954. Alphabetical list of Lengua Indian words with English equivalents (Paraguayan Chaco). Journal Soc. Américanistes 43: 85-107.

LOZANO, P. 1941. Descripción corográfica del Gran Chaco Gualamba. Publicaciones Especiales del Instituto de Antropología, Universidad Nacional de Tucumán, Tucumán.

MARANTA, A. A. 1987. Los recursos vegetales alimenticios de la etnía mataco del Chaco Centro Occidental. Parodiana 5: 161-237.

MARTÍNEZ CROVETTO, R. 1964. Estudios etnobotánicos. I. Los nombres de plantas y su utilidad, según los indios tobas del este del Chaco. Bonplandia 1: 279-333.

MARTÍNEZ CROVETTO, R. 1965. Estudios etnobotánicos. II. Nombres de plantas y su utilidad, según los indios vilelas del Chaco. Bonplandia 2: $1-28$.

MÉTRAUX, A. 1946. Ethnography of the Chaco. In: STEWARD, J. H. (ed.), Handbook of South American Indians, Bull. 143, 1: 197-370. Smithsonian Institution, Washington.

MOERMAN, D. E. 2010. Native American food plants. A Ethnobotanical Dicctionary. Timber Press, Portland.

MORELLO, J. \& G. HORTT. 1985. Changes in the areal extent of arable farming, stock raising and forestry in the South American Chaco. Appl. Geogr. Develop. 25: 109-127.

MORELlO, J. H., A. F. RODRÍGUEZ, \& M. SILVA. 2009. Clasificación de ambientes en áreas protegidas de las ecorregiones del Chaco Húmedo y Chaco Seco. In: MORELLO, J. H. \& A. F. RODRÍGUEZ (eds.), El Chaco sin bosque: La Pampa o el desierto del futuro, pp. 53-91. Orientación Gráfica Editora, Buenos Aires.

NOVARA, L. J. 2012. Araceae. In: NOVARA, L. J. (ed.), Flora del Valle de Lerma 1(18), pp. 1-18. Edición impresa 1993, edición digital 2012.

OSÁN DE PÉREZ SÁENZ, M. F. \& V. J. PÉREZ SÁENZ. 2006. Diccionario de americanismos en Salta y Jujuy (República Argentina). Arco Libros, Madrid.

PEÑA, R. 1976. Flora cruceña. Litografías e Imprentas Unidas, La Paz.

PLOWMAN, T. 1969. Folk uses of New World Aroids. Econ. Bot. 23: 97-122.

POLINI, G., R. ROMERO LÓPEZ, R. DEGEN de
ARRÚA, A. QUARTI, G. DELMÁS de ROJAS, Y. P. GONZÁLEZ VILLALBA \& O. C. AQUINO ALFONSO. 2013. Comer del monte. Plantas útiles del Chaco Central. Cooperazione Internazionale, Asunción.

POWELL, D. R. 2010. “...Y entonces llegó un inglés...”. Historia de la iglesia anglicana en el Chaco paraguayo. Iglesia Anglicana Paraguaya, Asunción.

RAGONESE, A. E. 1967. Vegetación y ganadería en la República Argentina. Colección Científica del INTA 5, Buenos Aires.

RATZLAFF, G. 2008. Cristianos evangélicos en la Guerra del Chaco 1932-1935. Edición del Autor, Asunción.

REITZ, R. P. 1957. Aráceas Catarinenses. Sellowia 8: 20-70.

RIVERA NÚÑEZ, D. \& C. OBÓN DE CASTRO. 1991. La guía de INCAFO de las plantas útiles y venenosas de la Península Ibérica y Baleares (excluidas medicinales). INCAFO, Madrid.

SAYAGO, M. 1969. Estudio fitogeográfico del norte de Córdoba. Bol. Acad. Nac. Ci. Republ. Argent. 46: 124-427.

SCARPA, G. F. 2000. Plants employed in traditional veterinary medicine by the Criollos of the Northwestern Argentine Chaco. Darwiniana 38: 253-265.

SCARPA, G. F. 2007. Hacia una etnotaxonomía vegetal chorote I: fitonimia, sistema nomenclatural y comparación dialectal. Suplemento Antropológico, Universidad Católica de Asunción 42(1): 81-119.

SCARPA, G. F. 2009. Etnobotánica médica de los indígenas chorote y su comparación con la de los criollos del Chaco Semiárido (Argentina). Darwiniana 47: 92-107.

SCARPA, G. F. 2012. Las plantas en la vida de los criollos del oeste formoseño. Medicina, ganadería, alimentación y viviendas tradicionales. Rumbo Sur, Buenos Aires.

SCHMEDA HIRSCHMANN, G. 1994. Etnobotánica ayoreo. Revista Universum, Universidad de Talca 1994: 107-156.

SCHMEDA HIRSCHMANN, G. 1998. Etnobotánica ayoreo. Contribución al estudio de la flora y vegetación del Chaco. XI. Candollea 53: 1-50.

SCHULTES, R. E. 1962. Plantae Colombianae. XVI. Plants as oral contraceptives in the Northwest Amazon. Lloydia 26: 67-74.

SCHULTES, R. E. \& R. F. RAFFAUF. 1990. The healing forest. Medicinal and toxic plants of the Northwest Amazonia. Dioscorides Press, Portland.

SCHULZ, A. G. 1976. Nombres comunes de las plantas. Edición de los Gobiernos de la Provincias del Chaco y Corrientes.

SOUTO, J. \& V. A. MILANO. 1966. Contenido en glicósidos cianogenéticos en Synandrospadix vermitoxicum (sacha-col). Revista Invest. Agropecu. 


\section{P. Arenas - Etnobotánica de Synandrospadix vermitoxicus}

Serie 2. Biol. Prod. Veg. 3(25): 385-391.

SPEGAZZINI, C. 1896. Planta novae V. Criticae Republicae Argentinae. Revista Fac. Agron. Univ. Nac. La Plata 2 (23-24): 382-392.

STAHL, W. 1982. Escenario indigena chaqueño. Pasado y presente. ASCIM, Filadelfia (Paraguay).

STAHL, W. 2007. Culturas en interacción. Una antropología vivida en el Chaco paraguayo. Editorial El Lector, Asunción.

SUÁREZ, M. E. 2012. Espíritus vinculados con el bosque y sus plantas en el mundo de los wichís del Chaco semiárido salteño, Argentina. In: ARENAS, P. (ed.), Etnobotánica en regiones áridas y semiáridas del Cono Sur de Sudamérica, pp. 145-177. Edición del CEFYBO-CONICET, Buenos Aires.

SUÁREZ, M. E. 2014. Etnobotánica wichi del bosque xerófito en el Chaco semiárido salteño. Editorial Autores de Argentina, Buenos Aires.

TÁRRAGA, F. \& G. T. HART. 1995. Etnobotánica guaraní. Centro de Estudios Regionales para el Desarrollo de Tarija (CER-DET), Aportes 2. Tarija.

TOURSARKISSIAN, M. 1980. Plantas medicinales de la Argentina. Sus nombres botánicos, vulgares, usos y distribución geográfica. Editorial Hemisferio Sur, Buenos Aires.
ULMKE, C. \& L. AUGUST. 2004. Kleiner Pflanzenführer für den paraguayischen Chaco. Una guia para plantas nativas del Chaco paraguayo. INTTAS Editor, Loma Plata (Chaco, Paraguay).

VILLAFUERTE, C. 1961. Voces y costumbres de Catamarca. Tomo 2 (L - Z). Academia Argentina de Letras, Buenos Aires.

VON REIS, S. \& F. J. LIPP. 1982. New plant sources for drugs and foods from The New York Botanical Garden Herbarium. Harvard University Press, Cambridge, Massachusetts.

YANOVSKY, E. 1936. Food plants of the North American Indians. Miscellaneous Publication $N^{\circ} 237$. United States Department of Agriculture, Washington.

ZANARDINI, J. \& W. BIEDERMANN. 2001. Los indígenas del Paraguay. Biblioteca Paraguaya de Antropología 39, Centro de Estudios Antropológicos de la Universidad Católica, CEADUC, Asunción.

Recibido el 22 de diciembre de 2015, aceptado el 25 de abril de 2016 . 
